\title{
Absolute Value of Bioelectrical Impedance Analysis-Measured Visceral Fat Area with Obesity-Related Cardiovascular Risk Factors in Japanese Workers
}

\author{
Yukiyoshi Okauchi ${ }^{1}$, Ken Kishida ${ }^{1}$, Tohru Funahashi ${ }^{1}$, Midori Noguchi², Tomoko Ogawa², Miwa Ryo ${ }^{1}$, \\ Kohei Okita ${ }^{1}$, Hiromi Iwahashi ${ }^{1}$, Akihisa Imagawa ${ }^{1}$, Tadashi Nakamura ${ }^{3}$, Yuji Matsuzawa ${ }^{4}$, \\ and lichiro Shimomura ${ }^{1}$ \\ ${ }^{1}$ Department of Metabolic Medicine, Graduate School of Medicine, Osaka University, Suita, Osaka, Japan \\ ${ }^{2}$ Amagasaki City Office, General Affairs Bureau, Personal Department, Payroll Section, Employee Health Promotion Section, \\ Amagasaki, Hyogo, Japan \\ ${ }^{3}$ Kawasaki Hospital, Kobe, Hyogo, Japan \\ ${ }^{4}$ Sumitomo Hospital, Osaka, Japan
}

\begin{abstract}
Aim: The accumulation of Visceral fat is known to precede metabolic disorders and atherosclerosis. This study aimed to determine the relationships between body mass index (BMI), waist circumference (WC), estimated visceral fat area (eVFA) measured by bioelectrical impedance analysis (BIA), and obesity-related cardiovascular risk factors.

Methods: The study population was 2,870 middle-aged Japanese employees (males/females=2,322/ 548), who had undergone a health check-up.

Results: In the receiver operating characteristic (ROC) curve, the cutoff levels yielding maximal sensitivity plus specificity for predicting the prevalence of $\geq 2$ risks were, $24.5 \mathrm{~kg} / \mathrm{m}^{2}$ for BMI, $84.6 \mathrm{~cm}$ for WC, and $111 \mathrm{~cm}^{2}$ for eVFA in males, and $23.6 \mathrm{~kg} / \mathrm{m}^{2}, 81.5 \mathrm{~cm}$, and $67 \mathrm{~cm}^{2}$ in females. The average number of risk factors was over 1.0 in those with a BMI $\geq 25 \mathrm{~kg} / \mathrm{m}^{2}$ and with a WC $\geq 85 \mathrm{~cm}$ for males, $\geq 28 \mathrm{~kg} / \mathrm{m}^{2}$ and $\geq 95 \mathrm{~cm}$ respectively for females, and those with an eVFA $\geq 100 \mathrm{~cm}^{2}$ for both males and females. In males, it was around 1.0 with cutoff levels of BMI, WC, and eVFA from the ROC curve. However, in females, it was around 0.6 , because the prevalence of subjects with obesity and multiple risks was very low.

Conclusions: These results suggested that the cutoff level for visceral fat reduction should be set based on an absolute value of risk factors, rather than a calculated value. In regular health check-up, it may be useful to set an absolute cutoff value for eVFA at $100 \mathrm{~cm}^{2}$ as criteria to screen for multiple obesity-related cardiovascular risk factors.
\end{abstract}

J Atheroscler Thromb, 2010; 17:1237-1245.

Key words; Visceral fat, Obesity-related cardiovascular multiple risk factors, Health check-up, Fat distribution, Bioelectrical impedance analysis

\section{Introduction}

Obesity is a major risk factor for hyperglycemia,

Address for correspondence: Ken Kishida, Department of Metabolic Medicine, Graduate School of Medicine, Osaka University, 2-2 B-5, Yamada-oka, Suita, Osaka 565-0871, Japan E-mail: kkishida@imed2.med.osaka-u.ac.jp

Received: April 20, 2010

Accepted for publication: July 13, 2010 diabetes, and hypertension. However, not all obese subjects have such disorders and, in Japan, mildly obese subjects sometimes have multiple obesity-related cardiovascular risk factors ${ }^{1-3)}$. We also demonstrated that a long period of exposure to multiple risk factors, including mild obesity, is involved in the onset of atherosclerosis in Japanese employees ${ }^{4)}$, and studies of Japanese-Americans in Hawaii and Seattle also suggest that the Japanese as a race can not handle glucose 
Table 1. Clinical characteristics of all subjects

\begin{tabular}{lcc}
\hline & Males $(n=2,322)$ & Females $(n=548)$ \\
\hline Age $($ year $)$ & $47.9 \pm 10.5(22-68)$ & $46.8 \pm 9.3(21-63)$ \\
Body Weight $(\mathrm{kg})$ & $69.1 \pm 9.2(42.6-110.2)$ & $56.3 \pm 7.7(39.7-100.3)$ \\
Body mass index $\left(\mathrm{kg} / \mathrm{m}^{2}\right)$ & $24.2 \pm 2.9(16.4-36.7)$ & $23.1 \pm 3.1(17.2-38.3)$ \\
Waist circumference $(\mathrm{cm})$ & $84.4 \pm 7.8(65.0-114.6)$ & $79.2 \pm 8.0(63.5-114.4)$ \\
Estimated visceral fat area $\left(\mathrm{cm}^{2}\right)$ & $99.6 \pm 38.9(14-254)$ & $62.4 \pm 31.1(22-220)$ \\
Systolic blood pressure $(\mathrm{mmHg})$ & $130.4 \pm 18.6(84-218)$ & $120.1 \pm 18.7(83-205)$ \\
Diastolic blood pressure $(\mathrm{mmHg})$ & $80.3 \pm 13.0(46-140)$ & $73.4 \pm 13.2(42-130)$ \\
Total cholesterol $(\mathrm{mmol} / \mathrm{L})$ & $5.24 \pm 0.89(2.51-9.69)$ & $5.37 \pm 0.91(2.98-9.40)$ \\
HDL cholesterol $(\mathrm{mmol} / \mathrm{L})$ & $1.46 \pm 0.42(0.47-3.34)$ & $1.69 \pm 0.44(0.52-3.99)$ \\
LDL cholesterol $(\mathrm{mmol} / \mathrm{L})$ & $2.90 \pm 0.76(0.44-7.04)$ & $2.93 \pm 0.79(0.70-6.58)$ \\
Triglyceride $(\mathrm{mmol} / \mathrm{L})$ & $1.96 \pm 1.47(0.29-19.91)$ & $1.25 \pm 0.94(0.28-14.9)$ \\
Glucose $(\mathrm{mmol} / \mathrm{L})$ & $5.96 \pm 1.80(3.16-24.9)$ & $5.56 \pm 1.43(3.39-25.8)$ \\
HbAlc $(\%)$ & $5.27 \pm 0.85(3.0-12.6)$ & $5.06 \pm 0.61(2.8-9.3)$ \\
\hline
\end{tabular}

Data are mean \pm SD (range).

HDL; high density lipoprotein, LDL; low density lipoprotein, HbA1c; hemoglobin A1c

metabolism as well as Caucasians when over-nourished and are liable to develop intolerance and complications even with a mild degree of adiposity ${ }^{5-7)}$. In fact, many obese Japanese have mild adiposity, compared with Europeans and Americans. Clinical research has demonstrated the distribution of body fat rather than the total amount of fat to be associated with obesity-related disorders ${ }^{1-3)}$. Recently, there is recognition that the distribution of body fat, especially visceral fat, accompanied by various metabolic disorders, should be distinguished from simple obesity. We and others have demonstrated that the accumulation of intraabdominal visceral fat precedes obesity-related metabolic disorders, including insulin resistance, glucose intolerance, dyslipidemia, and elevated blood pressure, leading to atherosclerosis based on a clustering of multiple risks ${ }^{1-3,8,9)}$. The Japanese Visceral Fat Syndrome Study Committee of the Ministry of Health and Welfare was organized to establish diagnostic criteria for obesity-related disease and visceral fat accumulation with obesity-related cardiovascular multiple risk factors ${ }^{10)}$. They have also set waist circumference (WC) as an embodiment of visceral fat accumulation ${ }^{10)}$. There, a WC over $85 \mathrm{~cm}$ in males and over $90 \mathrm{~cm}$ in females was decided according to the value of visceral fat area by computed tomography at the umbilical level, which was the cut-off for both male and females in terms of more than one cardiovascular risk factor ${ }^{10)}$. In this study ${ }^{10)}$, the relationship between visceral fat accumulation and the number of obesity-related cardiovascular risk factors was analyzed in 775 men (age, $55 \pm 11$ years, mean $\pm S D)$ and 418 women $(55 \pm 12$ years). However, there were some limitations as fol- lows, 1) the cutoff values for VFA were analyzed in men and women combined, 2) the study sample was relatively small for females, and 3) the study sample was not a general population but composed of outpatients receiving treatment for metabolic disorders. Previously, we also reported marked gender differences in the proportions of adiposity and marked acceleration of visceral fat accumulation after menopause in women ${ }^{11)}$. We established a new technique to noninvasively evaluate VFA using an abdominal bioelectrical impedance analysis (BIA) ${ }^{12}$. Accordingly, we assume that it is important to establish a correlation between BIA-measured visceral fat area and presence of obesity-related cardiovascular risk factors for middle-aged Japanese men and women, separately.

\section{Aim}

The aim of the present study is to establish gender-specific cutoff values for BIA-measured visceral fat area with obesity-related cardiovascular risk factors for urban Japanese workers.

\section{Subjects and Methods}

\section{Study Populations}

The study group comprised 2,870 Japanese who were employees of Amagasaki city office, Hyogo; an urban area, and had underwent an annual health check-up in 2004. Table 1 summarizes the profiles the of male and female subjects (males; $n=2,322$, females; $n=548$ ). The study was approved by the human ethics committee of Osaka University and written informed 
A

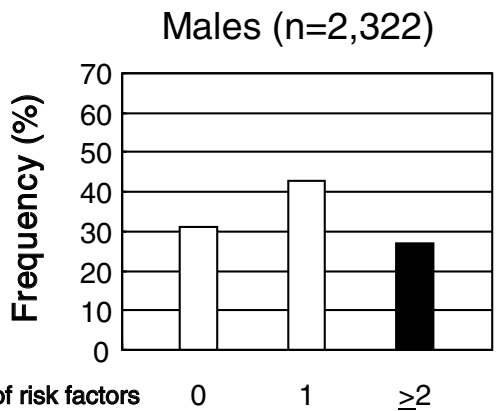

B

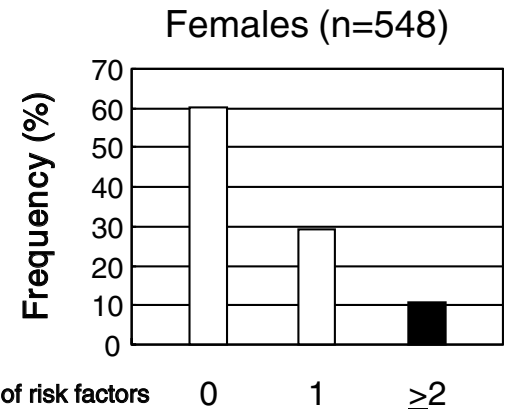

Fig. 1. The frequency of each number of obesity-related cardiovascular risk factors (elevated blood pressure, dyslipidemia, and hyperglycemia) in men (A) and women (B). Solid bar: subjects with two or more risk factors. We investigated the presence of three obesity-related cardiovascular risk factors: 1) elevated blood pressure (systolic blood pressure $(\mathrm{SBP}) \geq 130 \mathrm{mmHg}$ and/or diastolic blood pressure (DBP) $(\geq 85 \mathrm{mmHg}$ ), or regular treatment with anti-hypertensive agents), 2) dyslipidemia (hypertriglyceridemia (fasting or postprandial triglyceride of $\geq 1.69$ or $2.27 \mathrm{mmol} / \mathrm{L}$, respectively) ${ }^{16}$ ), and/or low HDL cholesterol (HDL cholesterol $<1.04 \mathrm{mmol} / \mathrm{L}$ ), or regular treatment with hypolipidemic agents), and 3) dysglycemia/impaired glucose tolerance (hyperglycemia (fasting or postprandial serum glucose concentration of $\geq 6.10$ or $7.77 \mathrm{mmol} / \mathrm{L}$, respectively) ${ }^{17)}$, or regular treatment with anti-diabetic agents).

consent was obtained from each participant. This trial (called The Amagasaki Visceral Fat Study) is registered with the University hospital Medical Information Network, number UMIN 000002391. We already reported the relationship between visceral fat accumulation and metabolic factors in the Amagasaki Visceral Fat Study ${ }^{13-15)}$, a study of middle-aged Japanese in whom visceral fat accumulation was estimated non-invasively by BIA, using a method described previously ${ }^{12)}$.

\section{Anthropometry and Laboratory Tests}

Height, weight and waist circumference were measured in a standing position. Waist circumference at the umbilical level was measured with a nonstretchable tape in late expiration while standing (in $\mathrm{cm})$. Visceral fat area (VFA) was estimated by BIA, as reported previously ${ }^{12)}$. Briefly, the voltage recorded at the flank to the flow of current between the umbilicus and the back correlates significantly with VFA and is not influenced by subcutaneous fat. We reported previously that VFA estimated by BIA (eVFA) correlates significantly with that determined by computed tomography $(\mathrm{CT})^{12}$. The coefficient of variation of BIA with the value of CT was $0.89 \%$ in the standing position and with late exhalation.

Blood pressure was measured with a standard mercury sphygmomanometer on the right arm after the subject had rested in a sitting position for at least 10 minutes. Venous blood samples were collected for measurements of blood glucose, high-density lipoprotein cholesterol (HDL-C), and triglyceride (TG) levels while the subject was in the supine position.

We investigated the presence of three obesityrelated cardiovascular risk factors (Fig. 1): 1) elevated blood pressure, 2) dyslipidemia, and 3) dysglycemia/ impaired glucose tolerance. Elevated blood pressure was represented by a systolic blood pressure (SBP) of $\geq 130 \mathrm{mmHg}$ and/or diastolic blood pressure (DBP) $\geq 85 \mathrm{mmHg}$, or regular treatment with anti-hypertensive agents. Dyslipidemia was represented by hypertriglyceridemia (fasting or postprandial triglyceride of $\geq 1.69$ or $2.27 \mathrm{mmol} / \mathrm{L}$, respectively) ${ }^{16)}$, and/or a low HDL cholesterol (HDL cholesterol $<1.04 \mathrm{mmol} / \mathrm{L}$ ), concentration or regular treatment with hypolipidemic agents. Dysglycemia/impaired glucose tolerance was represented by hyperglycemia (fasting or postprandial serum glucose concentration of $\geq 6.10$ or 7.77 $\mathrm{mmol} / \mathrm{L}$, respectively) ${ }^{17)}$, or regular treatment with anti-diabetic agents.

\section{Statistical Analysis}

A receiver operating characteristic (ROC) curve was used to determine the appropriate cutoff value for BMI, WC, and eVFA in identifying subjects with two or more of the above risk factors (Fig. 2). Differences in the mean number of obesity-related cardiovascular risk factors between males and females were analyzed with the Kruskal-Wallis test (Fig. 3). Linear regression and a quadratic curve were used to analyze the relationship between eVFA and WC (Fig.4). The level of significance was set at $p<0.05$. Continuous variables are presented as the mean \pm SD (Table 1 ) or mean \pm 
SEM (Fig. 3), as indicated. All statistical analyses were performed with StatView-J 5.0 (Statistical Analysis System Inc, Cary, NC) or the SPSS statistical software package (version 11.0.1J; SPSS, Chicago, IL).

\section{Results}

\section{Gender-Specific Receiver Operating Characteristic (ROC) Curve Analysis}

Table 1 shows the characteristics of the study population. The participants had a mean age 47.9 years for men and 46.8 years for women, a mean BMI of $24.2 \mathrm{~kg} / \mathrm{m}^{2}$ for men and $23.1 \mathrm{~kg} / \mathrm{m}^{2}$ for women, a mean WC of $84.4 \mathrm{~cm}$ for men and $79.2 \mathrm{~cm}$ for women, and a mean eVFA of $99.6 \mathrm{~cm}^{2}$ for men and $62.4 \mathrm{~cm}^{2}$ for women.

We analyzed the proportion of subjects with each number of obesity-related cardiovascular risk factors (Table 1). In males, 42.8\% $(n=993 / 2,322)$ had one risk factor, and $26.5 \%(n=616 / 2,322)$ had two or more (Fig. 1A). In females, 29.2\% $(n=160 / 548)$ had one risk factor, and $10.6 \%(n=58 / 548)$ had two or more (Fig. 1B). Furthermore, $60.2 \%$ of females $(n=$ 330/548) were free from any obesity-related cardiovascular risk (Fig. 1B), compared with only 30.7\% ( $n=$ 713/2,322) of males (Fig. 1A).

Fig. 2 shows the gender-specific ROC curves of BMI, WC and eVFA for detecting the clustering of obesity-related cardiovascular risk factors. The area under the curve (AUC) of BMI was 0.661 (95\%CI, 0.635-0.686) for males (Fig. 2A, left) and 0.705 (95\%CI, 0.629-0780) for females (Fig. 2A, right). The AUC of WC was $0.702(95 \% \mathrm{CI}, 0.678-0.72)$ for males (Fig. 2B, left) and 0.687 (0.613-0760) for females (Fig. 2B, right), and the AUC of eVFA was $0.711(0.688-0.734)$ for males (Fig. 2C, left) and 0.710 (0.637-0783) for females (Fig. 2C, right). Each AUC value was statistically significant for both males and females. There was no significant difference in the AUC values for BMI, WC and eVFA between males and females.

The cutoff levels yielding maximal sensitivity plus specificity for predicting the prevalence of two or more obesity-related abnormalities were, $24.5 \mathrm{~kg} / \mathrm{m}^{2}$ for BMI (Fig. 2A, left), $84.6 \mathrm{~cm}$ for WC (Fig. 2B, left), and $111 \mathrm{~cm}^{2}$ for eVFA (Fig. 2C, left), in males, and $23.6 \mathrm{~kg} / \mathrm{m}^{2}$ (Fig. 2A, right), $81.5 \mathrm{~cm}$ (Fig. 2B, right), and $67 \mathrm{~cm}^{2}$ (Fig. 2C, right). The cutoff level established from the ROC curve might be influenced by the characteristics of the study participants.
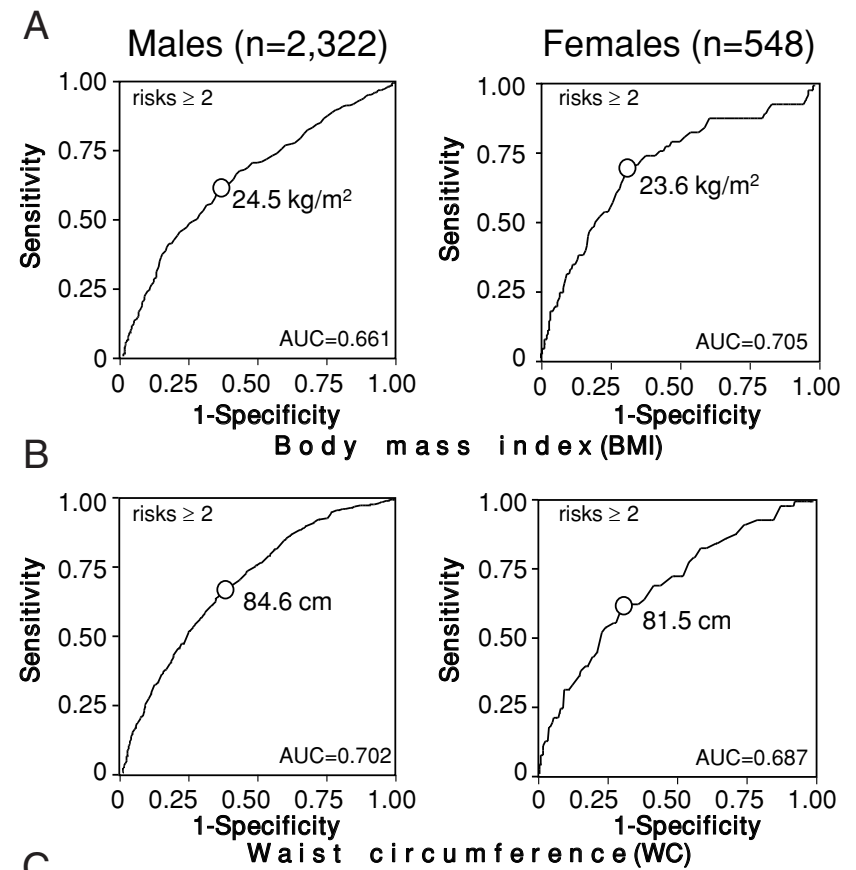

C

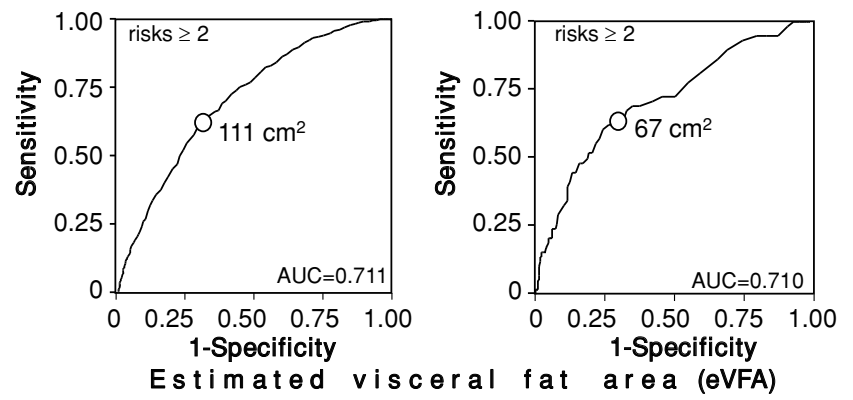

Fig. 2. The predictive performance of BMI (A), WC (B), and eVFA (C) for two or more obesity-related cardiovascular risk factors (elevated blood pressure, dyslipidemia, and hyperglycemia) according to the receiver operating characteristic (ROC) curve. The ROC curves for two or more risk factors in males (left) and females (right) are shown. Each optimal cut off point for identifying two or more risk factors estimated for the ROC curve is shown by a white circle. AUC; area under the specificity-sensitivity curve, 95\% CI; 95\% confidence intervals.

Gender-Specific Number of Obesity-Related Cardiovascular Risk Factors According to BMI, WC, and eVFA Levels, and Gender-Specific Body Fat Distribution

We evaluated the association between BMI, WC, or eVFA and the number of obesity-related cardiovascular risk factors. The male and female groups were divided into eight bins of BMI (every $1.5 \mathrm{~kg} / \mathrm{m}^{2}$, Fig. 3A, 3B), WC (every $5 \mathrm{~cm}$, Fig. 3C, 3D), and eVFA (every $20 \mathrm{~cm}^{2}$, Fig. 3E, 3F). 

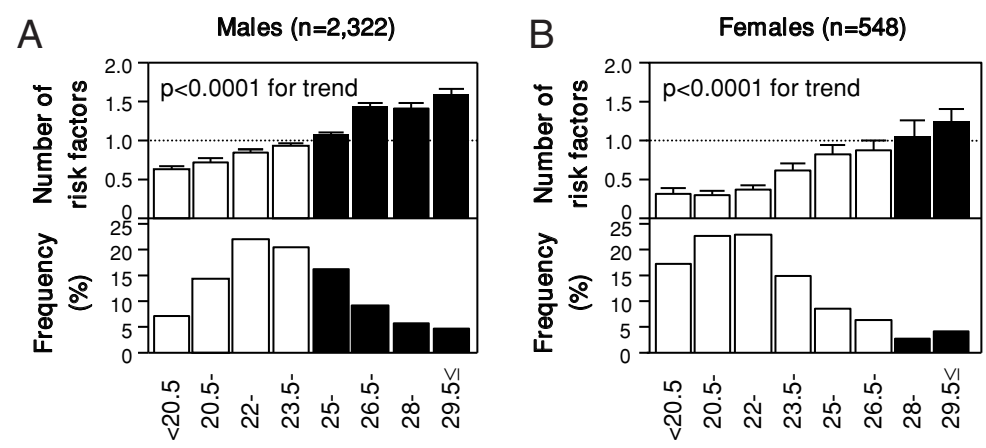

Body mass index (BMI) (kg/m²)

C
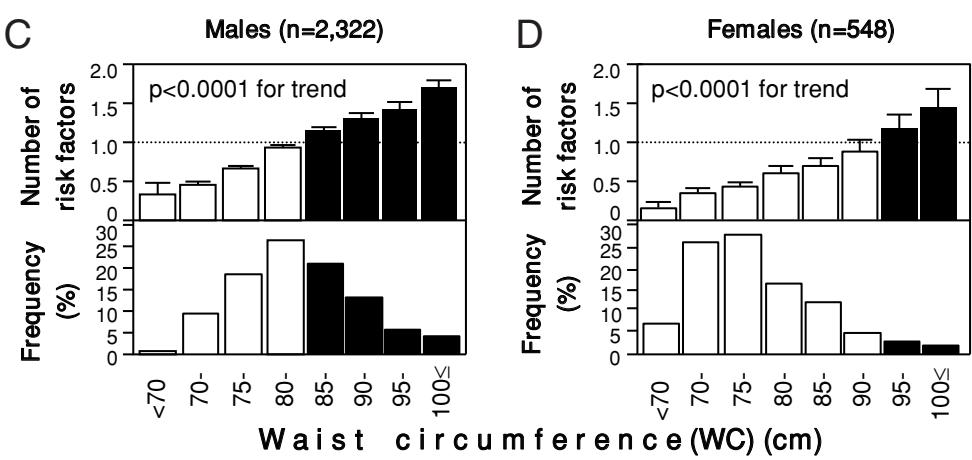

$E$
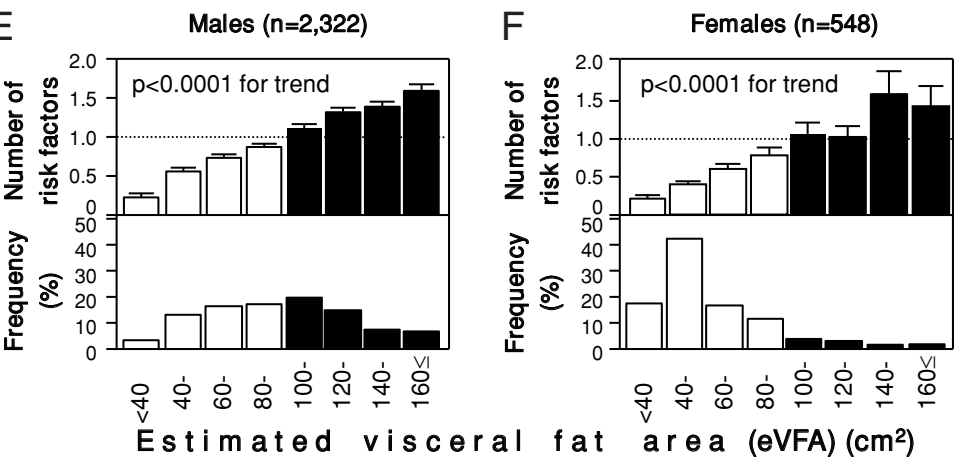

Fig. 3. Correlation between the average number of obesity-related cardiovascular risk factors (elevated blood pressure, dyslipidemia, and hyperglycemia) and body mass index (BMI) (top), and prevalence of BMI in each category divided by (every $1.5 \mathrm{~kg} / \mathrm{m}^{2}$ ) (bottom) in 2,322 males (A) and 548 females (B), and waist circumference (WC) (top), and prevalence of WC in each category divided by (every $5 \mathrm{~cm}$ ) (bottom) in males (C) and females (D), and estimated visceral fat area (eVFA) (top), and prevalence of eVFA in each category divided by (every $20 \mathrm{~cm}^{2}$ ) (bottom) in males (E) and females (F). The horizontal dotted lines represent an average number of metabolic risk factors of 1.0. Solid bars show each group in which the average number of obesity-related risk factors was over 1.0. Data are the mean \pm SEM. Differences in the mean number of obesity-related cardiovascular risk factors were analyzed by the Kruskal-Wallis test.

First, the mean number of obesity-related cardiovascular risk factors increased significantly with a higher BMI, in both males (Fig. 3A, upper panel) and females (Fig. 3B top) $(p<0.0001$ for trend, the Kruskal-Wallis test). Fig. 3A and $\mathbf{3 B}$ show that, the average number of risk factors was more than 1.0 (black bar) 
A

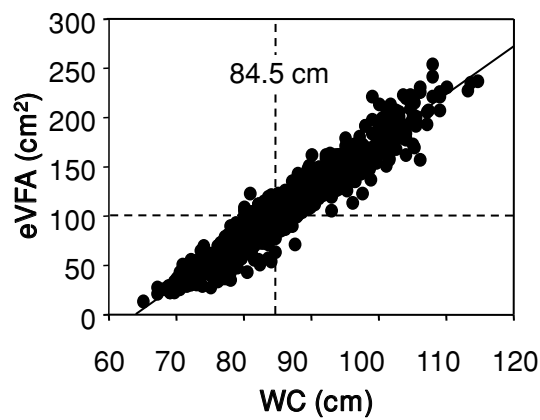

B

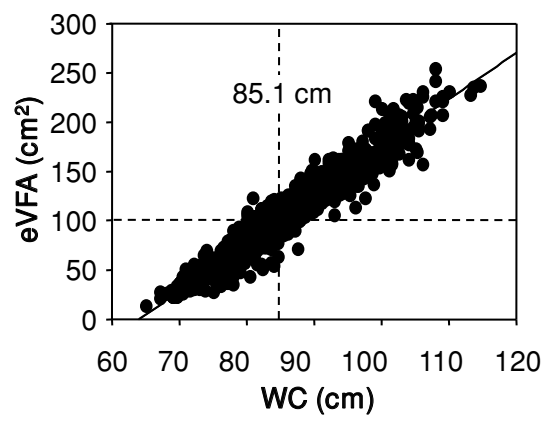

Females $(\mathrm{n}=548)$
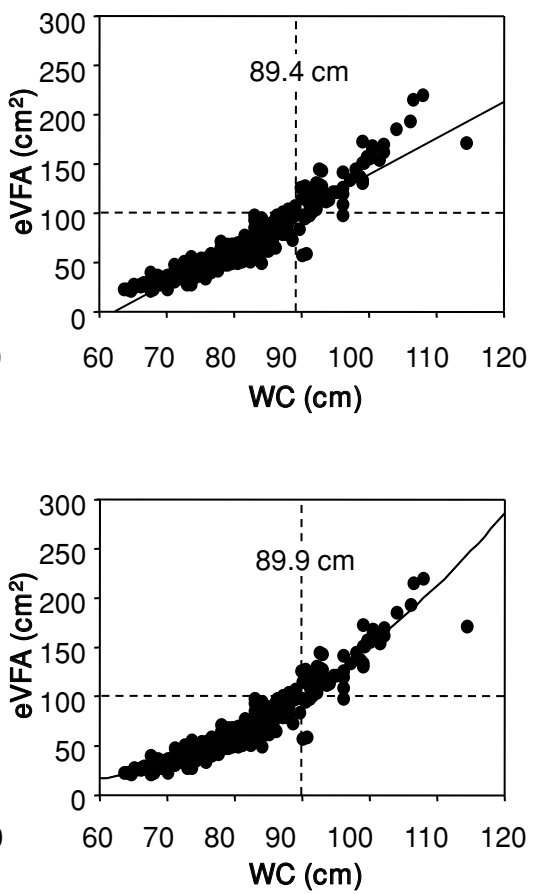

Fig.4. Regression line and quadratic curve for eVFA and WC in male and female subjects. The horizontal and vertical dotted lines represent an eVFA of $100 \mathrm{~cm}^{2}$ and WC corresponding to a VFA of $100 \mathrm{~cm}^{2}$ by a simple regression line (A) and quadratic curve (B).

at over $25 \mathrm{~kg} / \mathrm{m}^{2}$ for males and over $28 \mathrm{~kg} / \mathrm{m}^{2}$ for females. The proportion of subjects with a BMI $\geq 25$ $\mathrm{kg} / \mathrm{m}^{2}$ was $35.8 \%(n=832 / 2,322)$ for males (Fig. 3A, bottom, solid bars) and $21.9 \%$ for females $(n=120 /$ 548). That with a BMI $\geq 28 \mathrm{~kg} / \mathrm{m}^{2}$ was only $6.9 \%$ $(n=38 / 548)$ for females (Fig.3B, bottom, solid bars). When the BMI was $24.5 \mathrm{~kg} / \mathrm{m}^{2}$ for men, which is the cutoff level yielding maximal sensitivity plus specificity for predicting the prevalence of two or more obesity-related abnormalities using the ROC curve, the mean number of metabolic complications was approximately 1.0. In women, although the mean number of abnormalities increased as the BMI increased, it was around 0.6 with a BMI of $23.6 \mathrm{~kg} / \mathrm{m}^{2}$, which is the cutoff level from the ROC curve.

Second, the mean number of obesity-related cardiovascular risk factors increased significantly with a higher WC, in both males (Fig.3C top) and females (Fig. 3D, top) ( $p<0.0001$ for trend, the Kruskal-Wallis test). Fig. 3C and $3 \mathrm{D}$ show that, the average number of risk factors was more than 1.0 at a WC of over $85 \mathrm{~cm}$ for males and over $95 \mathrm{~cm}$ for females. In males, $44.5 \%(n=1,033 / 2,322)$ had a large WC $(\geq 85 \mathrm{~cm}$, solid bars) (Fig. 3C, bottom), while only 4.9\% ( $n=$ 27/548) of females had a large WC $(\geq 95 \mathrm{~cm}$, solid bars) (Fig. 3D, bottom). When WC was $84.6 \mathrm{~cm}$ for men, which is the cutoff level obtained from the ROC curve, the mean number of metabolic abnormalities was approximately 1.0. In women, although the mean number of abnormalities increased as WC increased, it was around 0.6 with a WC of $81.5 \mathrm{~cm}$, which is the cutoff obtained from the ROC curve.

Finally, the mean number of obesity-related cardiovascular risk factors increased significantly with a higher eVFA, in both males (Fig. 3E, top) and females (Fig. 3F, top) $(p<0.0001$, the Kruskal-Wallis test). The horizontal dotted lines in Fig. $\mathbf{3 E}$ and $\mathbf{3 F}$ represent eVFA of the $100-\mathrm{cm}^{2}$ category and the average number of risk factors of 1.0 for both male and female subjects. In males, $45.2 \%(n=1,049 / 2,322)$ had accumulated visceral fat (eVFA $\geq 100 \mathrm{~cm}^{2}$, solid bars) (Fig. 3E, bottom), while in females, this figure was $9.6 \%(n=57 / 548)$ (Fig. 3F, bottom). When the eVFA was $111 \mathrm{~cm}^{2}$ for men, the cutoff level from the ROC curve, the mean number of metabolic abnormalities was approximately 1.0. In women, although the mean 
number of abnormalities increased as the eVFA increased, it was around 0.6 with an eVFA of 67 $\mathrm{kg} / \mathrm{m}^{2}$, the cutoff level obtained from the ROC curve.

\section{Gender-Specific Correlation between eVFA and WC}

WC and eVFA were plotted using a simple regression equation and quadratic curve. Based on the simple regression equation, WC correlated with eVFA in both men $(p<0.0001, r=0.971)$ and women $(p<$ $0.0001, r=0.947)$; a WC value of $84.5 \mathrm{~cm}$ corresponded to an eVFA of $100 \mathrm{~cm}^{2}$ in males, while a WC of $89.4 \mathrm{~cm}$ corresponded to an eVFA of $100 \mathrm{~cm}^{2}$ in females (Fig. 4A). In addition, calculations using a quadratic curve showed that WC correlated with eVFA in both males $(p<0.0001, r=0.971)$ and females $(p<0.0001, r=0.963)$ : a WC of $85.1 \mathrm{~cm}$ corresponded to an eVFA of $100 \mathrm{~cm}^{2}$ in men whereas a WC of $89.9 \mathrm{~cm}$ corresponded to an eVFA of $100 \mathrm{~cm}^{2}$ in women (Fig. 4B).

\section{Discussion}

The present analysis of a large number of middle-aged Japanease demonstrated that the average number of obesity-related cardiovascular risk factors was more than 1.0 in those with a BMI over $25 \mathrm{~kg} / \mathrm{m}^{2}$ for males and over $28 \mathrm{~kg} / \mathrm{m}^{2}$ for females, in those with a WC over $85 \mathrm{~cm}$ for males and over $95 \mathrm{~cm}$ for females, and in those with an eVFA over $100 \mathrm{~cm}^{2}$ for both sexes. Several clinical studies have demonstrated that the accumulation of visceral fat is more closely associated with obesity-related metabolic disorders than is the BMI in Japanese ${ }^{1-3,13)}$. Therefore, waist circumference and eVFA may be more useful for detecting obesity-related cardiovascular risk factors than the BMI, although the current study showed the cutoff value for the BMI, over $25 \mathrm{~kg} / \mathrm{m}^{2}$ for males and over $28 \mathrm{~kg} / \mathrm{m}^{2}$ for females. The current study demonstrated a relationship between eVFA measured non-invasively and multiple cardiovascular risk factors.

Over-eating and physical inactivity cause visceral fat to accumulate, leading to the development of obesity-related risk factors and an increased risk of cardiovascular diseases ${ }^{1-3,8,9)}$. This condition is called "metabolic syndrome" ${ }^{18,19)}$ and prevalent in the general Japanese population ${ }^{20)}$. Metabolic syndrome is a useful clinical entity to predict cardiovascular risk, beyond the classic risk factors such as age, hypercholesterolemia and smoking ${ }^{21)}$. Therefore, a decrease in multiple risk factors by reducing accumulated visceral fat would be important in preventing cardiovascular diseases. Several studies reported that WC and VFA correlated with the number of cardiovascular risk factors in Japa- nese subjects ${ }^{10,22-29)}$. Some reports proposed using cutoff values for WC and VFA obtained from ROC curves $^{22-25}$, 28). Here, we performed a gender-specific ROC analysis to assess WC and eVFA as an indicator of at least two of the three obesity-related cardiovascular risk factors (Fig. 2). Similar to previous reports $^{22-25,29)}$, low cutoff points for WC and eVFA for women yielding maximal sensitivity plus specificity might lead to the detection of more subjects with metabolic abnormalities. However, as we showed here, among women with a significantly low prevalence of obesity-related abnormalities, low cutoff points resulted in a high rate of false positives, with women not at risk being identifiel as abnormal. Hence, the relative cutoff points for WC and eVFA for women from the ROC curve may not be effective to screen multiple obesity-related cardiovascular risk factors in middle-aged Japanese women in regular health checkups. Therefore, a proposed relative cut-off value of VFA estimated from the ROC curve in middle-aged Japanese females should be read with caution. These results suggested that the cutoff value for visceral fat reduction should be based on an absolute value, rather than a relative value calculated from the ROC curve, in middle-aged Japanese. More practically, the average number of risk factors was over 1.0 at an eVFA of 100 $\mathrm{cm}^{2}$ for both males (Fig. 3E, top) and females (Fig. 3F, top), indicating that an eVFA of over $100 \mathrm{~cm}^{2}$ to be suitable to screen multiple obesity-related cardiovascular risk factors in regular health check-ups.

One limitation of this study was that the mean age of the female subjects was 46.8 years (Table 1), relatively young compared to the age of retirement (age $\leq 60$ ). Therefore, the ratio of post-menoposal women was small. We and others have shown that visceral fat starts to accumulate after menopause in women ${ }^{11,30,31)}$. Hayashi et al. recommended an age-specific assessment of VFA when evaluating obesity-related cardiovascular risk factors in females ${ }^{32}$. Other studies have also confirmed increases in cardiovascular events and thr frequency of metabolic risk factors after menopause $^{33,34)}$. Taken together, it is possible that the female subjects in the present study were too young to assess the effect of visceral fat on the number of metabolic risk factors. In other words, adiposity and visceral fat may not matter as much in pre-menoposal women in terms of multiple obesity-related cardiovascular risk factors. Further study is needed to examine this issue in a large number of post-menopausal females with a wide range of body mass values.

Visceral adiposity is usually measured by computed tomography. However, the procedure is expensive, takes time, and involves radiation. The measure- 
ment of visceral adiposity by BIA (eVFA) is much more feasible and relatively reliable It may be meaningful that WC equivalent to a visceral fat area of 100 $\mathrm{cm}^{2}$ as estimated by BIA was $\cong 85 \mathrm{~cm}$ for males and $\cong 90 \mathrm{~cm}$ for females in middle-aged Japanese (Fig. 4).

\section{Conclusion}

In conclusion, setting an absolute cutoff value for BIA-measured visceral fat area when screening for multiple obesity-related cardiovascular risk factors rather than a relative cutoff value using the ROC curve in a general health check-up, may be effective in preventing cardiovascular diseases.

\section{Limitations of the Study}

Our study measured VFA by BIA. Measurements of both visceral and subcutaneous fat areas by computed tomography are more accurate. Subjects who were on medication for diabetes, hyperlipidemia, or hypertension were included (male; $n=513$, female; $n=71$ ). The results were similar to the eVFA value when subjects using medication were excluded (data not shown). The proportion of subjects who received blood tests postprandially anytime between the afternoon and early evening for the annual health check-up was $82.7 \%$ in males $(n=1921 / 2322)$ and $84.9 \%$ in females $(n=465 / 548)$. Therefore, we evaluated each parameter using postprandial criteria reported previously ${ }^{16,17)}$.

\section{Acknowledgements}

We thank all members of the Amagasaki Study Group in the Department of Metabolic Medicine, Osaka University and Amagasaki medical staff, especially Drs. Hitoshi Nishizawa, Sachiko Tamba, and Etsuko Akita, for the helpful discussion and comments.

This work was supported in part by Grant-in-aid for Scientific Research No. (C) 21591177 (to K.K.), a Research Grant (No.KH21AI005a) from the Ministry of Health, Labor and Welfare (to T.F.), a Japan Heart Foundation \& Astellas/Pfizer Grant for Research on Atherosclerosis (to K.K.), and a grant from the Manpei Suzuki Diabetes Foundation (to T. N.).

\section{Disclosure statement}

The authors have no conflict of interest to declare.

\section{References}

1) Fujioka $S$, Matsuzawa $Y$, Tokunaga K, Tarui S: Contribution of intra-abdominal fat accumulation to the impairment of glucose and lipid metabolism in human obesity. Metabolism 1987; 36: 54-59

2) Matsuzawa Y, Shimomura I, Nakamura T, Keno Y, Tokunaga K: Pathophysiology and pathogenesis of visceral fat obesity. Diabetes Res Clin Pract 1994; 24: S111-S116

3) Nakamura T, Tokunaga $K$, Shimomura I, Nakamura $T$, Tokunaga K, Shimomura I, Nishida M, Yoshida S, Kotani K, Islam AH, Keno Y, Kobatake T, Nagai Y, Fujioka S, Tarui S, Matsuzawa Y: Contribution of visceral fat accumulation to the development of coronary artery disease in non-obese men. Atherosclerosis 1994; 107: 239-246

4) Nakamura T, Tsubono Y, Kameda-Takemura K, Funahashi T, Yamashita S, Hisamichi S, Kita T, Yamamura T, Matsuzawa Y; Group of the Research for the Association between Host Origin and Atherosclerotic Diseases under the Preventive Measure for Work-related Diseases of the Japanese Labor Ministry: Magnitude of sustained multiple risk factors for ischemic heart disease in Japanese employees: a case-control study. Jpn Circ J 2001; 65: 1117

5) Fujimoto WY, Bergstrom RW, Boyko EJ, Leonetti DL, Newell-Morris LL, Wahl PW: Susceptibility to development of central adiposity among populations. Obes Res 1995; 3: S179-S186

6) Yano K, MacLean CJ, Reed DM, Shimizu Y, Sasaki H, Kodama K, Kato H, Kagan A: A comparison of the 12-year mortality and predictive factors of coronary heart disease among Japanese men in Japan and Hawaii. Am J Epidemiol 1988; 127: 476-487

7) Egusa G, Murakami F, Ito C, Matsumoto Y, Kado S, Okamura M, Mori H, Yamane K, Hara H, Yamakido M: Westernized food habits and concentrations of serum lipids in the Japanese. Atherosclerosis 1993; 100: 249-255

8) Despres JP, Lemieux I: Abdominal obesity and metabolic syndrome. Nature 2006; 444: 881-887

9) Kissebah AH, Vydelingum N, Murray R, Evans DJ, Hartz AJ, Kalkhoff RK, Adams PW: Relation of body fat distribution to metabolic complications of obesity. J Clin Endocrinol Metab 1982; 54: 254-260

10) Examination Committee of Criteria for 'Obesity Disease' in Japan; Japan Society for the Study of Obesity: New criteria for 'obesity disease' in Japan. Circ J 2002; 66: 987-992

11) Kotani K, Tokunaga K, Fujioka S, Kobatake T, Keno $Y$, Yoshida S, Shimomura I, Tarui S, Matsuzawa Y: Sexual dimorphism of age-related changes in whole-body fat distribution in the obese. Int J Obes Relat Metab Disord 1994; 18: 207-212

12) Ryo M, Maeda K, Onda T, Katashima M, Okumiya A, Nishida M, Yamaguchi T, Funahashi T, Matsuzawa Y, Nakamura T, Shimomura I: A new simple method for the measurement of visceral fat accumulation by bioelectrical impedance. Diabetes Care 2005; 28: 451-453

13) Okauchi $Y$, Nishizawa H, Funahashi T, Ogawa T, Noguchi M, Ryo M, Kihara S, Iwahashi H, Yamagata K, Nakamura T, Shimomura I, Matsuzawa Y: Reduction of visceral fat is associated with decrease in the number of met- 
abolic risk factors in Japanese men. Diabetes Care 2007; 30: 2392-2394

14) Tamba S, Nishizawa H, Funahashi T, Okauchi Y, Ogawa T, Noguchi M, Fujita K, Ryo M, Kihara S, Iwahashi H, Yamagata K, Nakamura T, Shimomura I, Matsuzawa Y: Relationship between the serum uric acid level, visceral fat accumulation and serum adiponectin concentration in Japanese men. Intern Med 2008; 47: 1175-1180

15) Okauchi Y, Kishida K, Funahashi T, Noguchi M, Ogawa T, Ryo M, Okita K, Iwahashi H, Imagawa A, Nakamura T, Matsuzawa Y, Shimomura I: Changes in serum adiponectin concentrations correlate with changes in BMI, waist circumference, and estimated visceral fat area in middleaged general population. Diabetes Care 2009; 32: e122

16) American Diabetes Association: Screening for type 2 diabetes. Diabetes Care 2000; 23 (Suppl. 1): S20-S23

17) Ahmad J, Hameed B, Das G, Siddiqui MA, Ahmad I: Postprandial hypertriglyceridemia and carotid intimamedia thickness in north Indian type 2 diabetic subjects. Diabetes Res Clin Pract 2005; 69: 142-150

18) Teramoto T, Sasaki J, Ueshima H, Egusa G, Kinoshita M, Shimamoto K, Daida H, Biro S, Hirobe K, Funahashi T, Yokote K, Yokode M: Metabolic syndrome. J Atheroscler Thromb 2008; 15: 1-5

19) Zimmet P, Magliano D, Matsuzawa Y, Alberti G, Shaw J: The metabolic syndrome: a global public health problem and a new definition. J Atheroscler Thromb 2005; 12: 295-300

20) Arai H, Yamamoto A, Matsuzawa Y, Saito Y, Yamada N, Oikawa S, Mabuchi H, Teramoto T, Sasaki J, Nakaya N, Itakura H, Ishikawa Y, Ouchi Y, Horibe H, Shirahashi N, Kita T: Prevalence of metabolic syndrome in the general Japanese population in 2000. J Atheroscler Thromb 2006; 13: 202-208

21) Teramoto T, Sasaki J, Ueshima H, Egusa G, Kinoshita M, Shimamoto K, Daida H, Biro S, Hirobe K, Funahashi T, Yokote K, Yokode M: Risk factors of atherosclerotic diseases. Executive summary of Japan Atherosclerosis Society (JAS) guideline for diagnosis and prevention of atherosclerosis cardiovascular diseases for Japanese. J Atheroscler Thromb 2007; 14: 267-277

22) Ohkubo T, Kikuya M, Asayama K, Imai Y: A proposal for the cutoff point of waist circumference for the diagnosis of metabolic syndrome in the Japanese population. Diabetes Care 2006; 29: 1986-1987

23) Hara K, Matsushita Y, Horikoshi M, Yoshiike N, Yokoyama T, Tanaka H, Kadowaki T: A proposal for the cutoff point of waist circumference for the diagnosis of metabolic syndrome in the Japanese population. Diabetes Care 2006; 29: 1123-1124
24) Nishimura R, Nakagami T, Tominaga M, Yoshiike $N$, Tajima N: Prevalence of metabolic syndrome and optimal waist circumference cut-off values in Japan. Diabetes Res Clin Pract 2007; 78: 77-84

25) Oka R, Kobayashi J, Yagi K, Tanii H, Miyamoto S, Asano A, Hagishita T, Mori M, Moriuchi T, Kobayashi M, Katsuda S, Kawashiri MA, Nohara A, Takeda Y, Mabuchi H, Yamagishi M: Reassessment of the cutoff values of waist circumference and visceral fat area for identifying Japanese subjects at risk for the metabolic syndrome. Diabetes Res Clin Pract 2008; 79: 474-481

26) Eguchi M, Tsuchihashi K, Saitoh S, Odawara Y, Hirano T, Nakata T, Miura T, Ura N, Hareyama M, Shimamoto K: Visceral obesity in Japanese patients with metabolic syndrome: reappraisal of diagnostic criteria by CT scan. Hypertens Res 2007; 30: 315-323

27) Miyawaki T, Hirata M, Moriyama K, Sasaki Y, Aono H, Saito N, Nakao K: Metabolic syndrome in Japanese diagnosed with visceral fat measurement by computed tomography. Proc. Japan Acad 2005; 81: 471-479

28) Sakurai M, Takamura T, Miura K, Kaneko S, Nakagawa H: Middle-aged Japanese women are resistant to obesityrelated metabolic abnormalities. Metabolism 2009; 58: 456-459

29) Kashihara H, Lee JS, Kawakubo K, Tamura M, Akabayashi A: Criteria of waist circumference according to computed tomography-measured visceral fat area and the clustering of cardiovascular risk factors. Circ J 2009; 73:1881-1886

30) Franklin RM, Ploutz-Snyder L, Kanaley JA: Longitudinal changes in abdominal fat distribution with menopause. Metabolism 2009; 58: 311-315

31) Toth MJ, Tchernof A, Sites CK, Poehlman ET: Menopause-related changes in body fat distribution. Ann N Y Acad Sci 2000; 904: 502-506

32) Hayashi T, Boyko EJ, McNeely MJ, Leonetti DL, Kahn SE, Fujimoto WY: Minimum waist and visceral fat values for identifying Japanese Americans at risk for the metabolic syndrome. Diabetes Care 2007; 30: 120-127

33) Oda E, Kawai R: Age- and gender-related differences in correlations between abdominal obesity and obesityrelated metabolic risk factors in Japanese. Intern Med 2009; 48: 497-502

34) Shiraishi J, Kohno Y, Sawada T, Nishizawa S, Arihara M, Hadase M, Hyogo M, Yagi T, Shima T, Nakazawa A, Shigeta M, Yamada H, Tatsumi T, Azuma A, Matsubara H; AMI-Kyoto Multi-Center Risk Study Group: Relation of obesity to acute myocardial infarction in Japanese patients. Circ J 2006; 70: 1525-1530 